\title{
斜方電弧熍接棒に上万機關車罐台桃の熔接 （昭籼22年5月19日揢接學會講演原稿）
}

正大貝大西，宸

\section{Abstract}

Welding of thick plate by "Side arc process."

Member $Y$. Ohrishi.

The purpose of this process is to get the are welded joint of thick plate economically. In this process the coating material of an electrode is partially removed (Fig. 3) so that the arc strike not only downwatd fron electrode tip but also extend to a side. The bytt pint of thick plate are prepared with deposite metals' as illustrated in 'Fig. 4. instead of .U or double-U scarfing. The grooved area $i, e$, gap of two plates is so narrow that an electrode can scarcely be permitted, to enter the space. Use this electrode when a sufficient penetration of deposite metal into the side wall (or beveled surface) is not obtained.

Mechanical strength and shrinkage of this joint are not inferrior to the joint of the usual method. This process is "suitable to the welding of thick plate especially the weld length is comparatively short. Frame work of a locomotive boiler bed could be welded economically by this process.

\section{丙 容 梗 概}

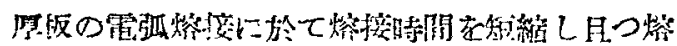

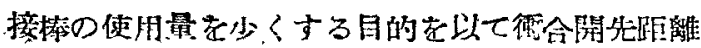

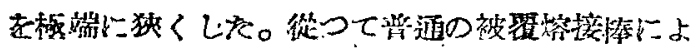

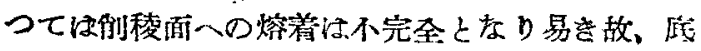

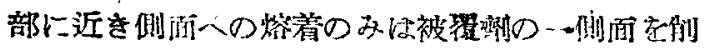
除せる聺接绩にて行つ\%。

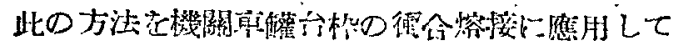

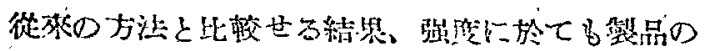

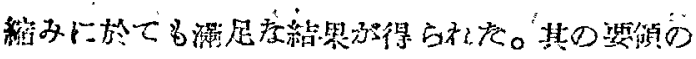

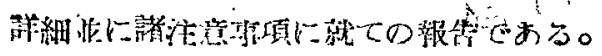

\section{1. 緒司}

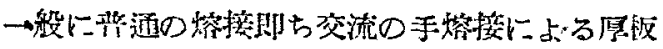

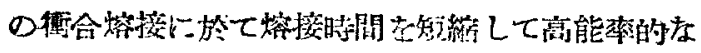

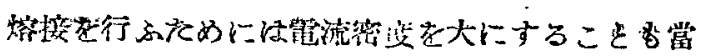

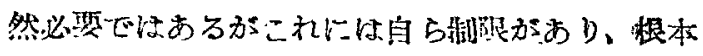

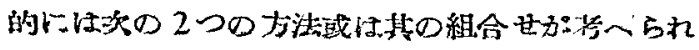

3。

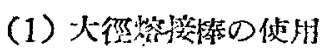

(2) 開先離距縮少

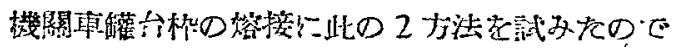

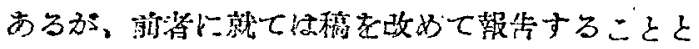

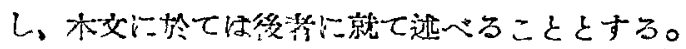

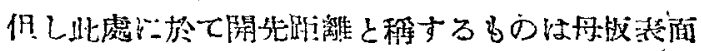

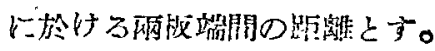

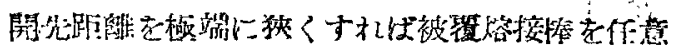

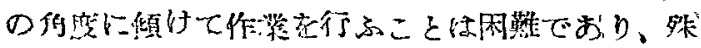

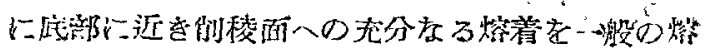

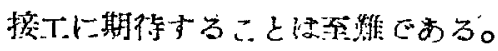

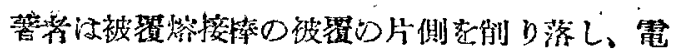

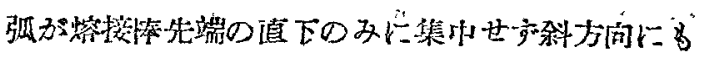

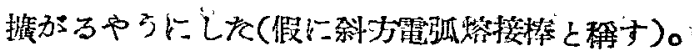

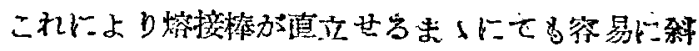

*大这大㲘教授, 工博

(1) Professor of the Osaka Univcrsity 


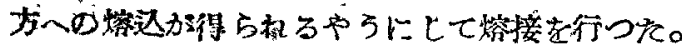

\section{2. 材の種類、形状並に從來の熔接方法}

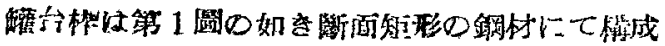

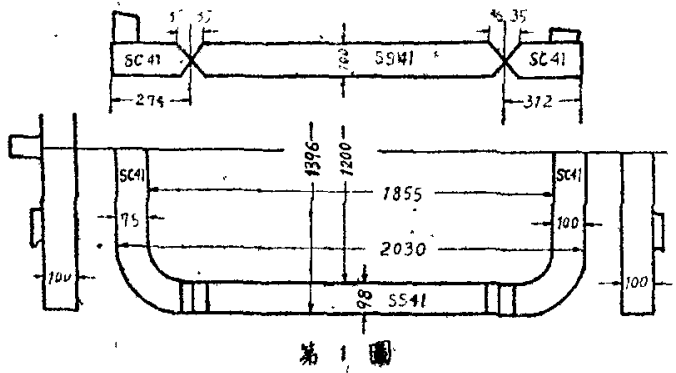

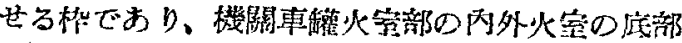

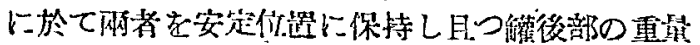

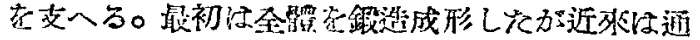

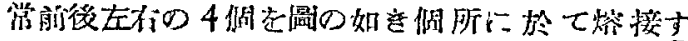

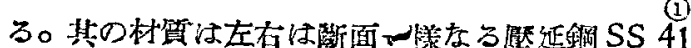
より成るが、角部及び啳部には尖起部があり因

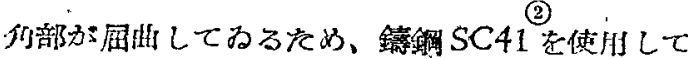

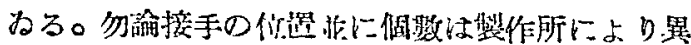

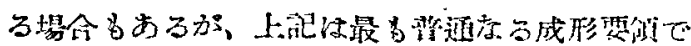
ある。

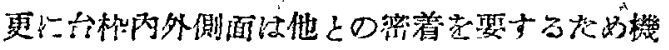

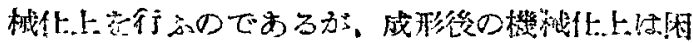

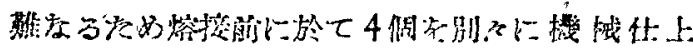

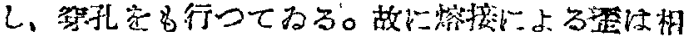

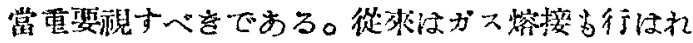

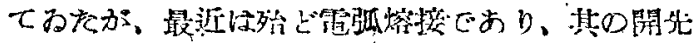

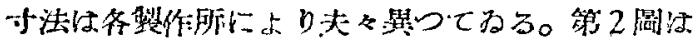
現在行はれでるる開先の形㸛、寸法を示す。

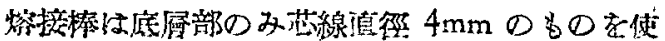

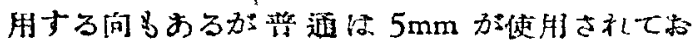

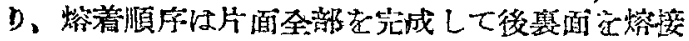

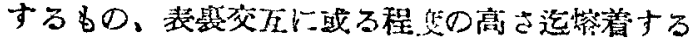

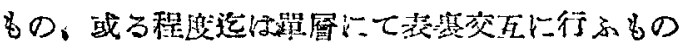

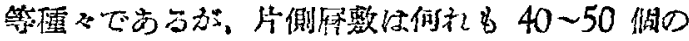

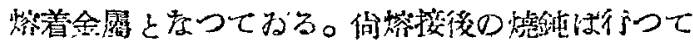
みない。

\section{3. 本赛驗に於ける烙接捧及び開先の準備}

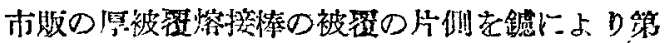

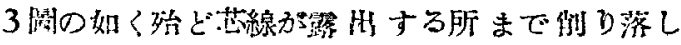

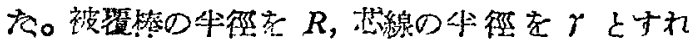
代侧除せる面積は $R^{2} \cos ^{-1}-\frac{\gamma}{R}-\sqrt{R^{2}-\gamma^{2}} \cdot \gamma$ にて 示される゙を以て $R^{2}-\gamma^{2}$ ○储則古们除したかが明

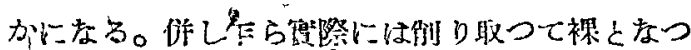

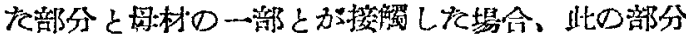

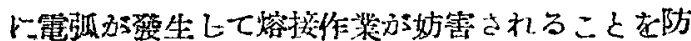

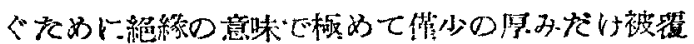
を㙛してるる。

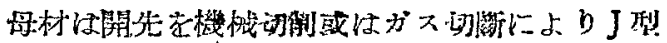

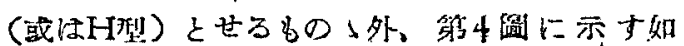

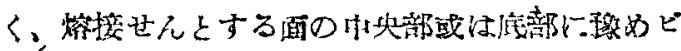

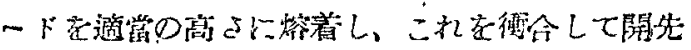

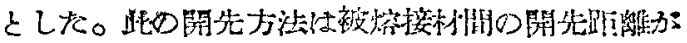

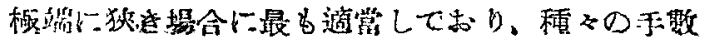

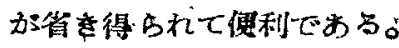




\section{4．斜方電弧による熔若金局の强度}

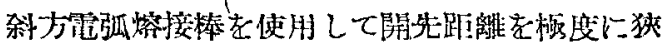

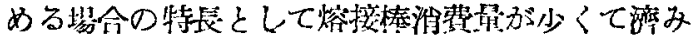

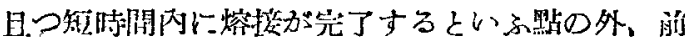
述の如く開先们稜の手數を少くする點が藇㥩られ るか゚、一方斜點として将へられる點は現在に於て

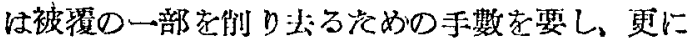

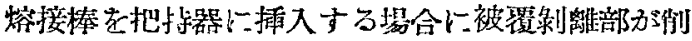
稜面に向くが如く插入しなければなら蛙入操作 が多少面倒となると冷入方れる點である。併し作

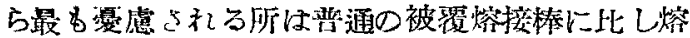
着金䐂の成綪加根本何に低下するやも知れてずとい

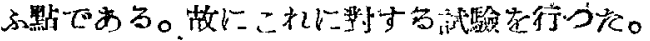
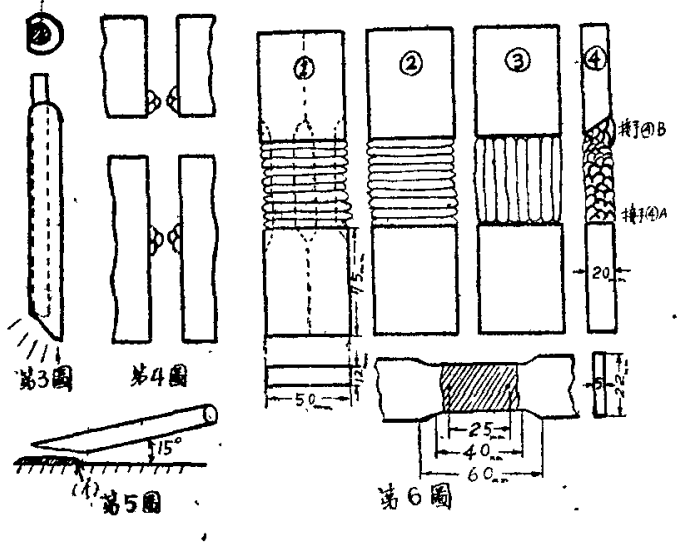

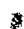

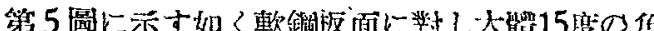

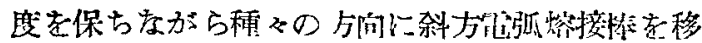

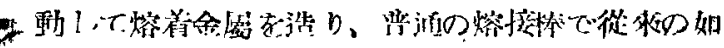

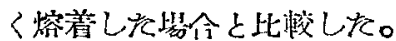

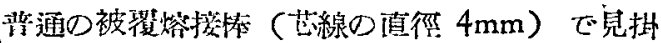

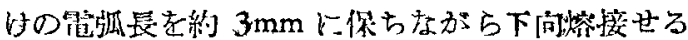

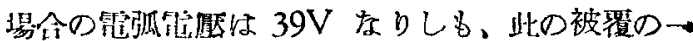

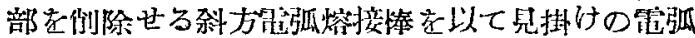
長老約 $3 \mathrm{~mm}$ 上保ちながら聂材面と15隻の们度に

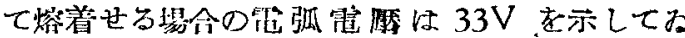

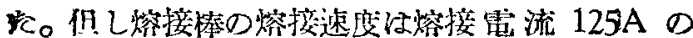

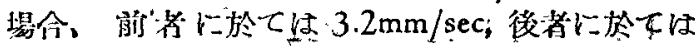

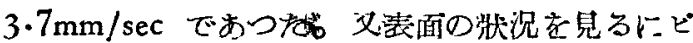
一ト゚の形狀には後者が特に異つてわる點は見以せ

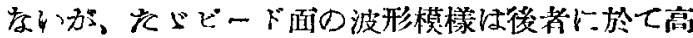
低が幾分著しい（俗に波形稍葑れてるる）やうで ある。叉揢揬電流を大とせる場合は科方電弧に於

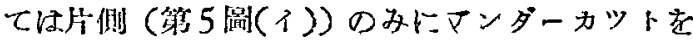
生じる僋问がある。

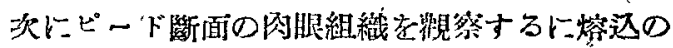

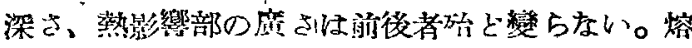

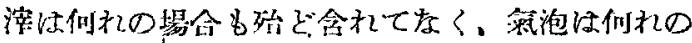
梤合も多少存在してわる。

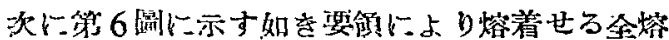

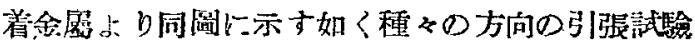

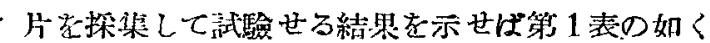

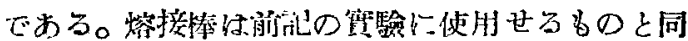

\begin{tabular}{|c|c|c|c|c|c|}
\hline 畨 號 & 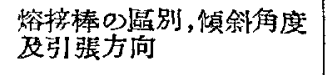 & $\begin{array}{l}\text { 引張强 } \\
\mathrm{kg} / \mathrm{mm}^{2}\end{array}$ & 伸 $(\mathrm{G} . \mathrm{L}=25 \mathrm{~mm})$ & 切 傡 個 所 & 断面 の菻况 \\
\hline 1 & 照通の被覆燃接棒, $90^{\circ}$ & 48,00 & 6.6 & 標點外（ビード队付） & 晨（小果泡むり） \\
\hline $\mathbf{1}^{\prime}$ & (ビードの方向に直角) & 5) 40 & 12.0 & $"$ & 定 \\
\hline 2 & 斜方奄泒熔摸棒, $15^{\circ}$ & 45.60 & 8.0 & $"$ & 是(僅に燿声むり) \\
\hline $2^{\prime}$ & (ビードの方向に直角) & $54: 70$ & 21.5 & 標點有（ビード中央） & 最辰。 \\
\hline 3 & 銘方電弧熔接棒, $15^{\circ}$ & 46.80 & 4.0 & 標點外・(ビード內) & 氣泡及熔溹むり \\
\hline $\mathbf{3}^{\prime}$ & (ビードの方向に平行 $)$ & 46.90 & 4.2 & 標點外（境 界 部） & 乘泡稍多乞 \\
\hline 4 & 斜方宅派窝接溙， $15^{\circ}$ & $\therefore 51.75^{\circ}$ & 15.0 & 摽點外 (ビード网) & 是 \\
\hline $4^{\prime}$ & (ビードの重りの方向) 作 & 55.40 & 12.0 & 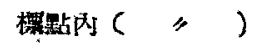 & 辰(僅に称むり) \\
\hline
\end{tabular}


格であり、塔接電流は 125Aである。

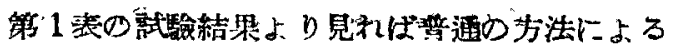

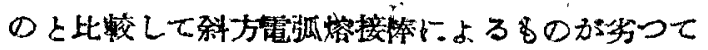

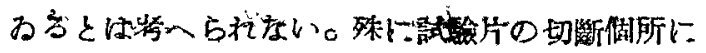

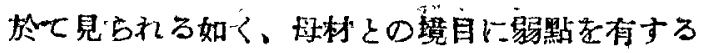

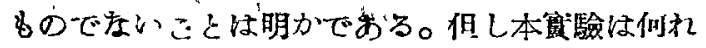
も下向熔接の結果であり、蓍者が止處に行はん亡 ナっ觹台枠の衙合熔接㤬として堅向摈着となる

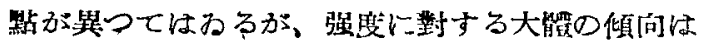
䂓ひ得られる。

\section{5. 台伜材の熔接}

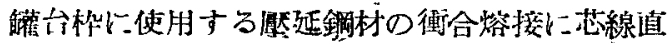

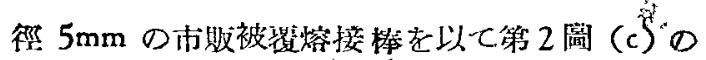

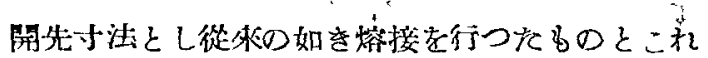

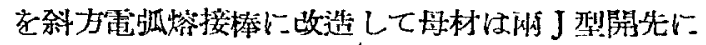

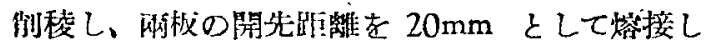

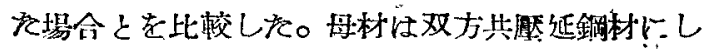

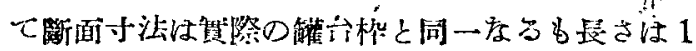

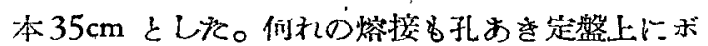
ールトにて母材学蟐めつけて行つを。

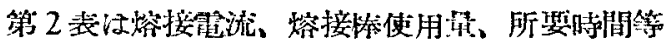

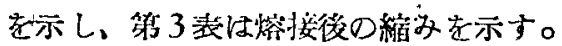

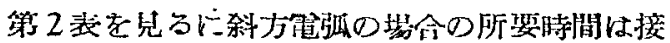

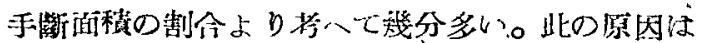

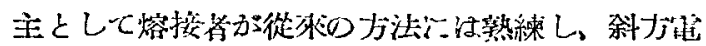

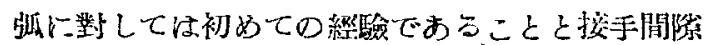

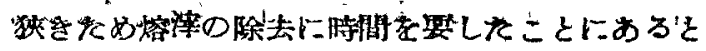

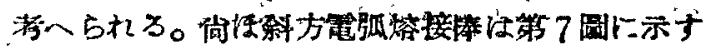

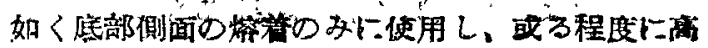

\begin{tabular}{|c|c|c|c|c|c|}
\hline & 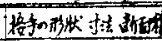 & 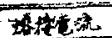 & 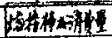 & $E-F \cap$ & 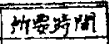 \\
\hline 离 & & 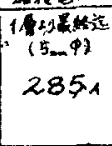 & $\begin{array}{c}4-8+2 m 20 \\
14770_{m \infty} \\
(100 \%)\end{array}$ & $\begin{array}{c}79 * \\
\left(\frac{1}{2} 40(7)\right.\end{array}$ & 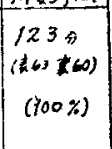 \\
\hline $\begin{array}{c}\text { 斜 } \\
3 \\
\text { 電 } \\
3\end{array}$ & $\sum_{\substack{13000 m^{2} \\
(16 \%)}}$ & 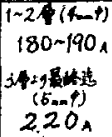 & $\begin{array}{l}95 \\
94 a b_{\text {an }} \\
(648)\end{array}$ & $\begin{array}{c}44 * \\
(126420)\end{array}$ & $\mid \begin{array}{c}97 * \\
(458.139) \\
(799)\end{array}$ \\
\hline
\end{tabular}

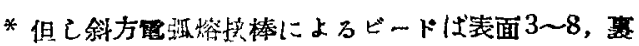
面 3〜10 むるのみ、他以全部曾通の被得淿接棒 にて行ふ
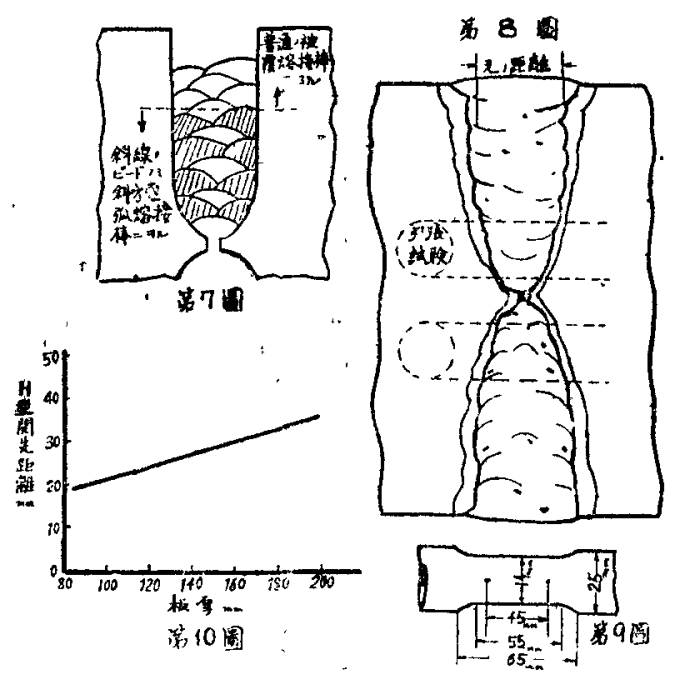

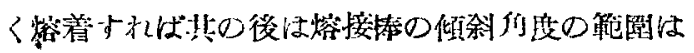

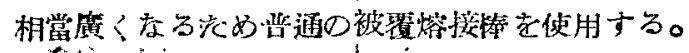

第3表熔接による䇥

\begin{tabular}{|c|c|c|c|c|}
\hline \multirow[t]{2}{*}{ 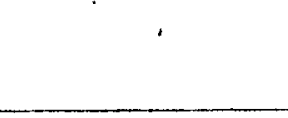 } & 普 通 & 0) 爟 接 & 斜 & 電 \\
\hline & 萎面 の㷊 & 側 面 $の$ 贸 & 要面の们 & 例面の正 \\
\hline 麦面のみ愘接せろ場合 & $\begin{array}{ll}-1 & (201) \\
+1 & (203)\end{array}$ & $\begin{array}{l}-0.5(201.5) \\
-0.4(202.5)\end{array}$ & $\begin{array}{ll}-2 & (200) \\
+2 & (201)\end{array}$ & $\begin{array}{l}-0.5(201.5) \\
-0.5(201.5)\end{array}$ \\
\hline 綌接な完了ざる䭪合 & $\begin{array}{r}-0.5(201.5) \\
+0.5(202.5)\end{array}$ & $\begin{array}{ll}0 & (202) \\
0 & (200)\end{array}$ & $\begin{array}{ll}0 & (202) \\
0 & (202)\end{array}$ & $\begin{array}{ll}0 & (202) \\
0 & (202)\end{array}$ \\
\hline
\end{tabular}




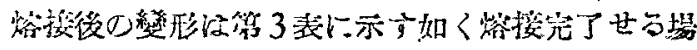

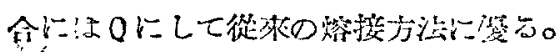

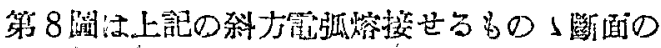

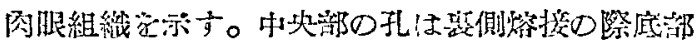

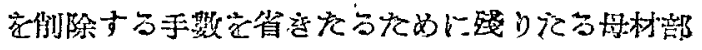

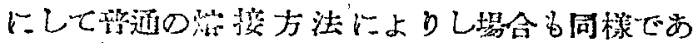

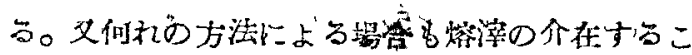

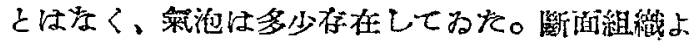

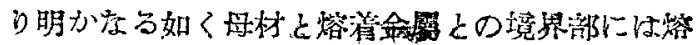

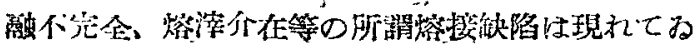
度的。

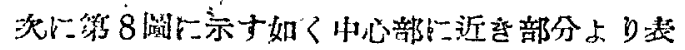

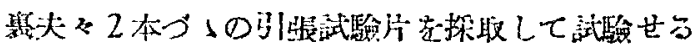

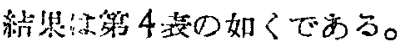

\begin{tabular}{|c|c|c|c|}
\hline & 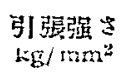 & 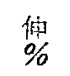 & 切疃 㧽 所 \\
\hline 表 面 & $\begin{array}{l}424 \\
39,6\end{array}$ & $\begin{array}{l}10.0 \\
12.0\end{array}$ & $\begin{array}{c}\text { 榕掏金闻中央部 } \\
\text { 同上 }\end{array}$ \\
\hline 輫 面 & $\begin{array}{l}40.8 \\
41.5\end{array}$ & $\begin{array}{r}9.0 \\
12.0\end{array}$ & $\begin{array}{l}\text { 同上 } \\
\text { 同上 }\end{array}$ \\
\hline
\end{tabular}

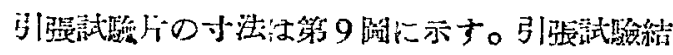

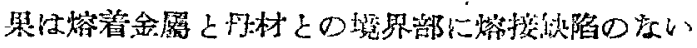

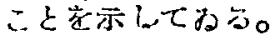

\section{6. 板厚と開先距離}

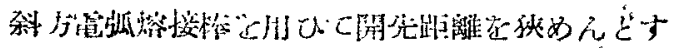

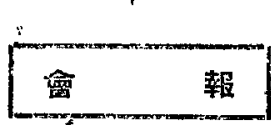

\section{第 2 回理軎}

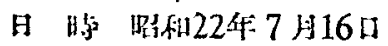

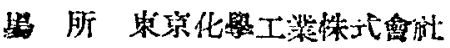

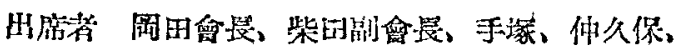

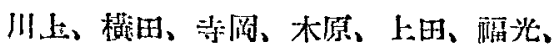

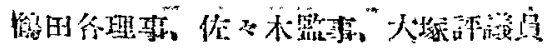

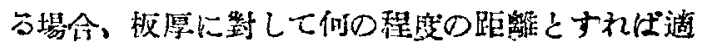

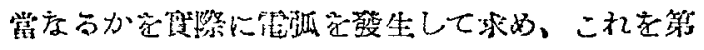

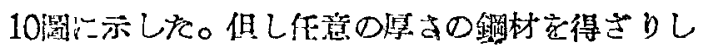

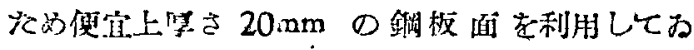

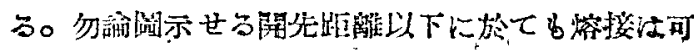

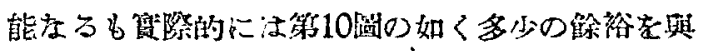

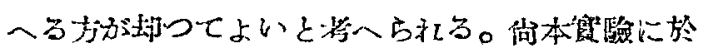

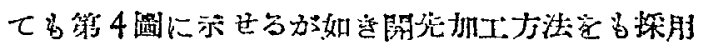
してみる。

\section{7. 結百}

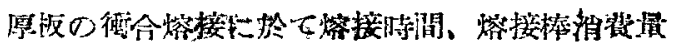

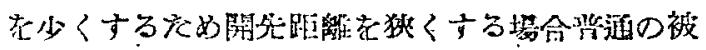

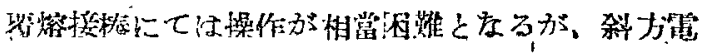

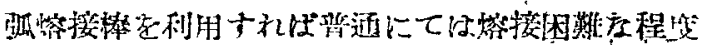

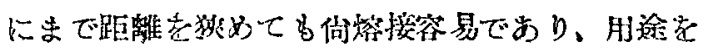

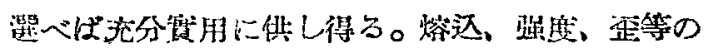
點に於ても信賴し得る。

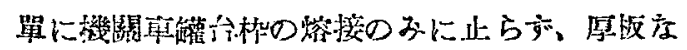

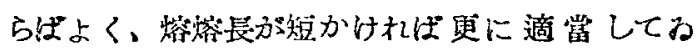

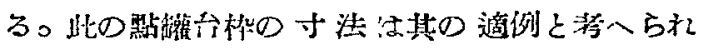

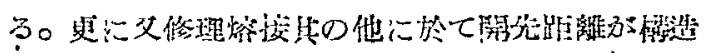

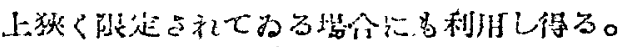

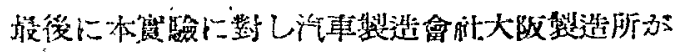

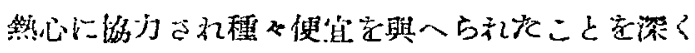

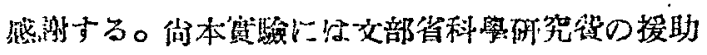
过得てるる。

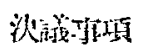

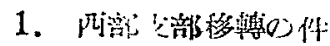

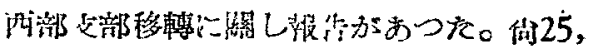

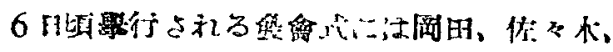

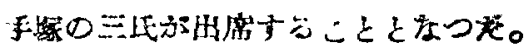

\section{2. 會勒排込口件}

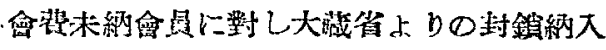

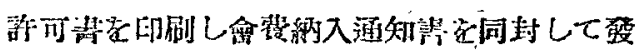

